\title{
Fake news em tempos de pandemia da covid- 19 e as repercussões na saúde mental
}

\section{False news in pandemic times from covid-1 9 and as repercussions on mental health}

\author{
Aline Raquel de Sousa Ibiapina' $\bullet$ Delmo de Carvalho Alencar ${ }^{2} \bullet$ Márcia Astrês Fernandes $^{3} \bullet$ Augusto Cezar \\ Antunes de Araújo Filho ${ }^{4}$
}

Nos últimos anos, a emergência e disseminação da World Wide Web e dos mecanismos de busca online contribuíram para que sites, blogs e portais virtuais passassem a ser cada vez mais utilizados como fonte de informação e aconselhamento sobre saúde. ${ }^{1,2}$ Cresce a quantidade de conteúdos sobre saúde, produzido e compartilhado online rapidamente. ${ }^{3} \mathrm{~A}$ Internet tem provocado profundas transformações nas relações econômico-sócio-culturais. Hoje, qualquer pessoa, com mínima habilidade tecnológica e condição financeira para aquisição de um dispositivo eletrônico, tem acesso a informações anteriormente restritas a segmentos privilegiados da sociedade. ${ }^{4} \mathrm{E}$ por vivermos na atualidade na era da informação e da comunicação digital, a busca por informações se dá em todos os contextos, inclusive na área da saúde, indo desde conselhos de um estilo de vida saudável até o tratamento de doenças, permitindo que o fácil acesso a estas informações transformem os indivíduos em colaboradores mais ativos e capacitados na gestão de sua própria saúde.

Mas, a Internet também possui algumas limitações: a qualidade da informação oferecida, muitas vezes incompleta, contraditória, incorreta, excessiva ou até fraudulenta, podendo gerar conselhos prejudiciais ou incorretos que levam à redução da confiança e controle. ${ }^{5}$

A produção e propagação massiva de notícias falsas - Fake News encontram um terreno fértil nos sites de redes sociais $^{6}$ e podem induzir os pacientes a erros nas decisões pessoais e cuidados com sua saúde. A doença do novo coronavírus, oficialmente denominado SARS-COV-2, agente etiológico da doença COVID-19, surgiu no final de dezembro de 2019 em Wuhan, província de Hubei na China, e logo depois se espalhou de forma transcontinental. Considerada pela Organização Mundial da Saúde (OMS) como uma emergência de saúde pública, dada pela gravidade do surto. ${ }^{7}$

As políticas de conscientização da população para permanecerem em casa e o distanciamento social desencorajaram muitas atividades do cotidiano das pessoas e modificaram seus estilos de vida e padrões de comportamento. O isolamento social e a solidão como resultado das políticas de permanência em casa contribuíram para o aumento do comprometimento da saúde mental da população global, em especial das pessoas que convivem com doenças crônicas.

Assim, níveis elevados de ansiedade, estresse e depressão podem estar relacionados a fatores como medo da infecção, distanciamento social, quarentena ou isolamento por causa do impacto econômico e ocupacional, medo de ficar doente e morrer; evitação de procurar um serviço de saúde por outros motivos, por receio de se contaminar; preocupação com a obtenção de alimentos, remédios ou suprimentos pessoais, dentre outras situações ${ }^{8}$

Estudo sobre as implicações do novo coronavírus no âmbito da saúde mental, realizado com a população geral da China, incluindo I.210 participantes, identificou a presença de sintomas de estresse, ansiedade e depressão. Cerca de $72 \%$ dos participantes relataram medo de que seus familiares adquirissem o vírus, fatores como: ser mulher, estudar, trabalhar, apresentar sintomas prévios da COVID-I 9 foram associados a elevados níveis de comprometimento men-

NOTA

I Enfermeira, Doutora em Enfermagem pelo Programa de Pós-Graduação em Enfermagem da Universidade Federal do Piauí (PPGEnf/UFPI). Docente do curso Bacharelado em Enfermagem da Universidade Federal do Piauí (UFPI), Campus Senador Helvídio Nunes de Barros. Picos, Piauí, Brasil. E-mail: alineraquel8@ hotmail.com;

2 Enfermeiro, Doutorando em Saúde Pública pela Escola Nacional de Saúde Pública, Fundação Oswaldo Cruz (ENSP/FIOCRUZ).Teresina, Piauí, Brasil. E-mail: delmo-carvalho@hotmail.com;

3 Enfermeira, Doutorado em Enfermagem Fundamental pela Escola de Enfermagem de Ribeirão Preto da Universidade de São Paulo (EERP/USP). Docente Associada do Departamento de Enfermagem da Universidade Federal do Piauí (UFPI), Campus Universitário Ministro Petrônio Portella. Teresina, Piauí, Brasil. E-mail:m.astres@ufpi.edu.br;

4 Enfermeiro, Doutor em Enfermagem pelo Programa de Pós-Graduação em Enfermagem da Universidade Federal do Piauí (PPGEnf/UFPI). Docente do curso Bacharelado em Enfermagem da Universidade Estadual do Piauí (UESPI), Campus Josefina Demes. Floriano, Piauí, Brasil. E-mail: araujoaugusto@hotmail.com. 
tal. ${ }^{9}$ No entanto, os participantes que receberam informações fidedignas sobre a doença, prevenção, transmissão e tratamento apresentaram menor comprometimento mental, evidenciando o efeito maléfico das Fake News na saúde emocional da população durante a pandemia da COVID-19.

Diante disso, recomenda-se à população sempre verificar a fonte propagadora do conteúdo, considerando que a qualidade das informações são fatores contribuintes na prevenção do adoecimento mental. $O$ combate às notícias falsas requer investimentos em educação e literacia digital e que as instituições aumentem o nível de confiabilidade das informações acessíveis para toda a população. A literacia digital em saúde, compreendida como a habilidade dos indivíduos em buscar informações sobre saúde nas mídias digitais, interpretá-las e qualificá-las frente a uma situação para adotar os conhecimentos a fim de solucionar um problema de saúde, é considerada um desafio para criar mecanismos para empoderar os usuários no reconhecimento de informações confiáveis provenientes do ambiente virtual, tornando-se urgente a necessidade de ações governamentais que invistam em educação formal ${ }^{10} \mathrm{e}$, por conseguinte, a melhoria do empoderamento da população para o autocuidado em seus aspectos tanto físico quanto psicoemocional. 


\section{REFERÊNCIAS}

I. Li J, Theng Y, Foo S. Predictors of online health information seeking behavior: changes between 2002 and 2012. Health Informatics Journal. 2016; 22(4):804-8I4.

2. Lin WY, Zhang X, Song H, Omori K. Health information seeking in the Web 2.0 age: trust in social media, uncertainty reduction, and self-disclosure. Comput Human Behavior. 2016; 56:289-294.

3. Kim Y. Is seeking health information online different from seeking general information online? Journal of Information Science. 20I5; 4 I (2):228-24I.

4. Pereira Neto AF, Paolucci R, Daumas RP, Souza RV.Avaliação participativa da qualidade da informação de saúde na internet: o caso de sites de dengue. Cien Saud Colet. 2017; 22(6): 1955-1968.

5. Moorhead SA, Hazlett DE, Harisson L, Carroll JK, Irwin A, Hoving C. Uma nova dimensão dos cuidados de saúde: revisão sistemática dos usos, benefícios e limitações das mídias sociais para a comunicação em saúde. JMIR. 2013; I5(4):e85.

6. Ellison NB, Boyd DM. Sociality through social network sites.
The Oxford handbook of internet studies. Oxford: Oxford University Press; 2013.

7. Wu F, Zhao S, Yu B, Chen Y, Wang W, Song Z, et al. A new coronavirus associated with human respiratory disease in China. Nature. 2020;579(7798):265-9. doi: 10.1038/ s4I586-020-2008-3.

8. WORLD HEALTH ORGANIZATION. Mental Health and Psychosocial Considerations During COVIDI9 Outbreak. Disponível em: https://www.who.int/docs/default-source/ coronaviruse/mental-health-considerations.pdf. Acesso em 03/I I/2020.

9. Wang C, Pan R, Wan X, Tan Y, Xu L, Ho CS, et al. Immediate psychological responses and associated factors during the initial stage of the 2019 Coronavirus Disease (COVID-19) epidemic among the general population in China. Int J Environ Res Public Health. 2020; I7(5): I 729.

10. Yamaguchi MU, Barros JK, Souza RCB, Bernuci MP, Oliveira LP. O papel das mídias digitais e da literacia digital na educação não-formal em saúde. Revista Eletrônica de Educação. 2020; | $4: 1-1 \mid$. 